\title{
USO COMBINADO DE 1-METICICLOPROPENO Y EMULSIONES DE CERA EN LA CONSERVACIÓN DE GUANÁBANA (Annona muricata) ${ }^{1}$
}

\author{
EFIGENIA MONTALVO GONZÁLEZ², ANDRES ELOY LEÓN FERNÁNDEZ, \\ HERNANI REA PAEZ ${ }^{3}$, MIGUEL MATA MONTES DE OCA², BEATRIZ TOVAR GÓMEZ ${ }^{2}$
}

RESUMEN- El objetivo de este trabajo fue evaluar la combinación del 1-metilciclopropeno (1-MCP) y emulsiones de cera sobre la conservación de guanábana. Las condiciones de almacenamiento fueron: $25^{\circ} \mathrm{C}$ y $16{ }^{\circ} \mathrm{C}$, frutos con emulsiones a base de cera de candelilla o cera de abeja diluídas con agua $(10: 90 \mathrm{v} / \mathrm{v}$ y $15: 85 \mathrm{v} / \mathrm{v})$ almacenados a $16^{\circ} \mathrm{C}$, frutos tratados con 1-MCP $\left(1500 \mathrm{~nL} \mathrm{~L}^{-1}, 12 \mathrm{~h}\right)$. En los frutos a $16^{\circ} \mathrm{C}$ con y sin emulsiones se observó daño por frío y no maduraron. En los frutos con la aplicación de 1-MCP solo o combinado con emulsiones, en cualquiera de las dilusiones, no se observaron síntomas daño por frío en la pulpa. La combinación de 1-MCP y emulsión a base de cera de abeja en dilución 15:85 v/v conservaron a los frutos de guanábana por 14-15 días en comparación con los frutos almacenados a $25^{\circ} \mathrm{C}$ (6 días).

Términos para indexacion: Annona muricata, 1-metilciclopropeno, emulsiones.

\section{USO COMBINADO DE 1-METICICLOPROPENO E EMULSÕES DE CERA NA CONSERVAÇÃO DA GRAVIOLA (Annona muricata)}

RESUMO - O objetivo deste estudo foi avaliar a combinação do 1-metilciclopropeno ( 1-MCP) e as emulsões de cera sobre a conservação da graviola . As condições de armazenamento foram: $25^{\circ} \mathrm{Ce} 16^{\circ} \mathrm{C}$, as emulsões de cera de abelha diluída com água ( 10:90 v/v , 15:85 v/v), os frutos foram tratados com 1 - MCP (1,500 $\mathrm{nL} \mathrm{L}-1,12 \mathrm{~h}$ ). Em frutos a $16^{\circ} \mathrm{C}$ com ou sem cera apresentaram danos por frio e não amadureceram. Em frutos com a aplicação de 1-MCP isolada ou em combinação com a cera, em qualquer das diluições, os sintomas de dano por frio na polpa não foram observados. A combinação de 1-MCP e com base de emulsão de cera de abelha na diluição 15:85 v/v mostrou uma vida útil de 14-15 dias, em comparação com os frutos armazenados a $25^{\circ} \mathrm{C}$ a qual foi de seis dias.

Termos para indexação: Annona muricata , 1-metilciclopropeno, emulsões.

\footnotetext{
1(Trabalho 281-13). Recebido em: 17-01-2014. Aceito para publicação em: 07-08-2013.

${ }^{2}$ Prof. Dres. En Ciencias en Alimentos. Laboratorio Integral de Investigación en Alimentos (LIIA), Instituto Tecnológico de Tepic, Avenida Insurgentes \#2595, Colonia Lagos del Country, Tepic, Nayarit. Código Postal 63175. México. E-mails:efimontalvo@ gmail.com; miguema@gmail.com; btovar@gmail.com

${ }^{3}$ Maestros en Ciencias en AlimentosLaboratorio Integral de Investigación en Alimentos (LIIA), Instituto Tecnológico de Tepic, Avenida Insurgentes \#2595, Colonia Lagos del Country, Tepic, Nayarit. Código Postal 63175. México. E-mails: eloyleon87@ gmail.com; zapotanito_16@hotmail.com
} 


\section{INTRODUCCIÓN}

Nayarit, México tiene el primer lugar en producción nacional de guanábana; sin embargo, este fruto presenta un problema de mercadeo por su alta perecibilidad. Una tecnología aplicada en la guanábana para conservación en fresco, es la aplicación de 1-metilciclopropeno (1-MCP).

Espinosa et al. (2012) reportaron que en los frutos de guanábana tratados con 200 y $400 \mathrm{~nL} \mathrm{~L}^{-1}$ por $24 \mathrm{~h}$ y almacenados a $16^{\circ} \mathrm{C}$, se conservaron por 10 días. Otra metodología empleada para alargar la vida de anaquel de los frutos perecederos, es el uso de emulsiones a base de ceras (CISNEROS; KROCHTA, 2002). Debido al efecto que han tenido los recubrimientos y el 1-MCP en la conservación de frutas, se ha estudiado el efecto sinérgico de estas dos tecnologías. Lima et al. (2004, 2010), aplicaron Fruit wax ${ }^{\circledR}$ a frutos de guanánaba 'Morada' y posteriormente aplicaron $200 \mathrm{~nL} \mathrm{~L}^{-1} \mathrm{de}$ 1-MCP por $12 \mathrm{~h}$ a una temperatura de $15^{\circ} \mathrm{C}$, estos autores concluyeron que la aplicación de $200 \mathrm{~nL}$ $\mathrm{L}^{-1}$ de 1-MCP por sí solo o combinado con la cera, no representó un aumento en el almacenamiento postcosecha, y resultó más eficiente el tratamiento de Fruit wax ${ }^{\circledR}$ que el 1-MCP.

Las diferentes variedades de anonáceas pueden responder de manera distinta a la aplicación de 1-MCP solo o combinado con recubrimientos; así, la respuesta al 1-MCP puede depender de la variedad y la forma en que se aplique (BLANKESHIP; DOLE, 2003). En este trabajo se evaluó el efecto de la combinación de emulsiones diluidas en agua, con el 1-MCP, en el proceso de maduración de la guanábana.

\section{MATERIALES Y METODOS}

El fruto de guanábana fue cosechado en madurez fisiológica en huertos de El Tonino municipio de Compostela, Nayarit, México. A las frutas se les aplicó por 5 min una solución de 2-4-tiazolil-1H-bencilimidazol (20 $\left.\mathrm{mg} \mathrm{L}^{-1}\right)$, para prevenir el crecimiento microbiano, y se secaron al ambiente $\left(23-25^{\circ} \mathrm{C}\right)$.

El almacenamiento fue como sigue: a $25^{\circ} \mathrm{C}$, a $16{ }^{\circ} \mathrm{C}$ (GR), frutos con emulsión a base de cera de candelilla o cera de abeja diluidas con agua en relación 10:90 v/v (C10:90, F10:90) y 15:85 v/v (C15:85, F15:85) almacenados a $16{ }^{\circ} \mathrm{C}$, frutos tratados con
1-MCP $\left(1500 \mathrm{~nL} \mathrm{~L}^{-1}, 12 \mathrm{~h}\right.$ a $\left.20^{\circ} \mathrm{C}\right)$ almacenados a 16 ${ }^{\circ} \mathrm{C}$, frutos tratados 1-MCP $\left(1500 \mathrm{~nL} \mathrm{~L}^{-1}, 12 \mathrm{~h} \mathrm{a} 20^{\circ} \mathrm{C}\right)$ y después recubiertos con las emulsiones en relación 10:90 v/v (1-MCP+C10:90, 1-MCP+F10:90) y 15:85 $\mathrm{v} / \mathrm{v}(1-\mathrm{MCP}+\mathrm{C} 15: 85,1-\mathrm{MCP}+\mathrm{F} 15: 85)$ almacenados a $16{ }^{\circ} \mathrm{C}$. Las emulsiones de candelilla y cera de abeja, se aplicaron por aspersión, con un contenido de sólidos de $24 \%$ y $20 \%$ respectivamente y fueron donadas por la empresa MULTICERAS S.A de C.V.

Para la aplicación del 1-MCP, los frutos se introdujeron a una cámara de $225 \mathrm{~L}$ y se colocó el 1-MCP diluído en agua y al lado de recipiente de liberación, se colocó un ventilador de $9 \mathrm{~V}$ (SmartFresh $^{\mathrm{TM}}$ Technology, AgroFresh Inc. PA, USA). La velocidad de respiración (VR) y velocidad de producción de etileno (VPE) se determinaron de acuerdo a la técnica reportada por TOVAR et al. (2001). Los gases se midieron en un cromatógrafo de gases marca HP, modelo 6890.

El porcentaje de pérdida de peso fue determinada pesando seis frutos diariamente por tratamiento, en una báscula Denver Instrument. La firmeza $(\mathrm{N})$ del fruto entero se determinó con un penetrómetro marca Shimpo, con un puntal plano de $5 \mathrm{~mm}$. Los sólidos solubles totales (SST en ${ }^{\circ} \mathrm{Brix}$ ) se determinaron en la pulpa mediante un refractómetro Atago (AOAC, 1984). La acidez titulable (AT, \% de ácido málico) se determinó usando la técnica de la AOAC (1984). El pH se determinó con un potenciómetro Jenco (Modelo 1671) (AOAC, 1984). Todos los análisis se realizaron por triplicado.

El color $\left({ }^{\circ} \mathrm{Hue}\right)$ de la cáscara fue medido en nueve áreas alrededor del fruto con un colorímetro Minolta CR300. El daño por frío fue medido visualmente identificando oscurecimiento en la cáscara y pulpa y se calculó el porcentaje de frutos que presentaron síntomas de daño por frío en un lote de 20 frutos por tratamiento. Se realizaron dos repeticiones del experimento.

Los datos se analizaron con un análisis de varianza (GLM-ANOVA) usando el paquete estadístico SAS (SAS System for windows ${ }^{\mathrm{TM}}$ ). La comparación de medias se realizó usando la prueba de $\operatorname{LSD}(\alpha=0.05)$.

\section{RESULTADOS Y DISCUSIÓN}

En la Figura 1A se observa que en los frutos a $25^{\circ} \mathrm{C}$, el pico climatérico se presentó el día 6 con $125.5 \mathrm{~mL} \mathrm{CO}_{2} \mathrm{~kg}^{-1} \mathrm{~h}^{-1}$. En los frutos GR (Figura 1A) y 
con emulsiones a las dos diluciones (Figura 1B y 1C), la VR alcanzó valores máximos entre 47.89 y 56.20 $\mathrm{mL} \mathrm{CO} \mathrm{kg}^{-1} \mathrm{~h}^{-1}$ pero no se presentó un climaterio definido. Estos resultados se consideran anormales y se atribuyen al daño por frío observado en los frutos (ver Figura 3) (PAREEK et al., 2011).

En los frutos con 1-MCPy 1-MCP+emulsiones (Figura 1B y 1C), la VR fue estadísticamente menor $(p<0.05)$ durante los primeros 8 días de almacenamiento que todos los tratamientos y fue dependiente de la dilución; además, se presentó el climaterio hasta los 12 días de almacenamiento. El retraso de la VR en éstos frutos, se atribuye al efecto sinérgico del 1-MCP y emulsiones, ya que por un lado el 1-MCP reduce el metabolismo respiratorio y por otro lado las emulsiones disminuyen el intercambio de oxígeno en la epidermis de las frutas disminuyendo la VR (ZHANG et al., 2011; FALGUERA et al., 2011).

Lima et al. (2010) reportaron que la aplicación de cera en guanábana 'Morada' fue más eficiente en la calidad de la fruta que el 1-MCP e incluso que la combinación cera+1-MCP. Esto significa que la variedad estudiada en este experimento, tiene una respuesta diferente al 1-MCP que la variedad 'Morada'. En los frutos a $25^{\circ} \mathrm{C}$ (Fig 1D) se detectó una producción máxima de VPE al día $7(40.85 \mu \mathrm{L}$ de etileno $\left.\mathrm{kg}^{-1} \mathrm{~h}^{-1}\right)$, mientras que en los frutos GR y con emulsiones a las dos diluciones, la VPE fue menor debido a que se ha comprobado que las bajas temperaturas disminuyen la actividad de las enzimas que intervienen en la síntesis del etileno (JIANG et al., 2004).

El 1-MCP retrasó la VPE de los frutos por 8 días y los resultados coinciden con la disminución del etileno en aguacate tratados con 1-MCP, concluyendo que el 1-MCP disminuye la expresión y síntesis de las enzimas que sintetizan etileno (ZHANG et al., 2011; PIRIYAVINIT et al., 2011). En los frutos con 1-MCP combinado con las emulsiones, los valores máximos de la VPE fueron entre 3.19-5.96 $\mu \mathrm{L}$ de etileno $\mathrm{kg}^{-1}$ $\mathrm{h}^{-1}$; una reducción de la VPE tres veces menor que los frutos GR y dos veces menor que los frutos con emulsiones a las dos diluciones (Figura 1E y 1F).

El resultado es atribuido a la potencia del 1-MCP para disminuir la acción y síntesis del etileno; y al mismo tiempo a la interacción de la barrera proporcionada por la cera en la superficie del fruto, que limita la disponibilidad interna de oxígeno, mismo que puede disminuir la actividad de la ACC oxidasa (BLANQUESHIP; DOLE, 2003; LIMA et al., 2010).

Se observó una menor pérdida de peso en los frutos GR, C10:90, F10:90, C15:85 y F15:85 en comparación con los frutos almacenados a 25 ${ }^{\circ} \mathrm{C}$ (Figura 2A, 2B y 2C); sin embargo, fue evidente que los frutos recubiertos con las emulsiones a 16 ${ }^{\circ} \mathrm{C}$ disminuyen en mayor proporción la pérdida de peso de los frutos no recubiertos y refrigerados (GR). Esto es porque se conoce que la temperatura de refrigeración disminuye la transpiración de frutas al disminuir su respiración, así mismo se sabe que puede ocurrir una mayor reducción de la pérdida de agua de frutos con la aplicación de recubrimientos en los mismos (SAUCEDO et al., 2009).

Los frutos con 1-MCP y tratados con 1-MCP+emulsiones también redujeron la pérdidad de peso; no obstante la aplicación combinada de 1-MCP y emulsiones a la dilución 15:85 fue más efectiva, ya que los frutos con 1-MCP $+\mathrm{C} 15: 85$ y 1-MCP+F15:85 presentaron $3.13 \%$ y $3.12 \%$ de pérdida de peso, respectivamente (ver Figura 2C). Esto se explica porque el 1-MCP redujo la VR y la emulsión posiblemente redujo la pérdida de agua en denpendencia de la dilución (BARITELLE et al., 2001).

En la Figura 2D se observa que los frutos almacenados a $25{ }^{\circ} \mathrm{C}$ tuvieron una firmeza final de 9.41 N (día 8). Los frutos GR y con emulsiones a las dos diluciones (Figura 2E y 2F), no alcanzaron la firmeza de madurez de consumo $(55.43-56.33 \mathrm{~N}$, día 10) debido al daño por frío. En los frutos tratados con 1-MCP la pérdida de firmeza fue menor respecto a los frutos almacenados a $25{ }^{\circ} \mathrm{C}$; sin embargo, en los frutos tratados con 1-MCP + emulsiones se retrasó el ablandamiento e iniciaron la pérdida de firmeza hasta el día 4 de almacenamiento, siendo el tratamiento de 1-MCP+F15:85 el que retardó por más tiempo la pérdida de firmeza $(9.5 \mathrm{~N}$ a los 14 días de almacenamiento).

Se ha comprobado que tanto el 1-MCP como los recubrimientos, por separado, pueden retrasar la pérdida de firmeza por la disminución de la actividad de las enzimas que degradan la pared celular como son celulasas, poligalacturonasas y $\beta$-galactosidasas (JEONG et al., 2002; LIMA et al., 2010; ZHOU et al., 2011). Por lo tanto, es posible que la combinación de ambos resulte más efectiva, como se pudo observar en este experimento.

Los SST en los frutos a $25^{\circ} \mathrm{C}$ fueron de 18.65 
${ }^{\circ}$ Brix (Cuadro 1). En los frutos GR el incremento de SST fue de $14.29^{\circ}$ Brix y fueron estadísticamente iguales ( $p>0.05$ ) a los encontrados en los frutos con emulsiones a las dos diluciones, considerando que el resultado se debió a que los frutos no maduraron. En contra parte, los frutos tratados con 1-MCP maduraron normalmente $\left(21.03{ }^{\circ} \mathrm{Brix}\right)$ al igual que los frutos con 1-MCP+emulsiones, aunque éstos últimos retrasaron el aumento de los SST.

Recientes estudios han demostrado que el 1-MCP regula la expresión genética del metabolismo de los carbohidratos, retrasando su degradación (TIWARI; PALIYATH, 2011). La AT aumentó y el pH disminuyó en frutos almacenados a $25^{\circ} \mathrm{C}$, la AT osciló entre $0.95-1.12 \%$ de ácido málico y el pH final fue igual a 3.73. Los frutos GR y los tratados con emulsiones a las dos diluciones, tuvieron un $\mathrm{pH}$ de 4.47 y de AT de 0.45-0.72\% de ácido málico, es decir la AT, no ascendió como es característico de un fruto de guanábana maduro. A diferencia de éstos, los frutos tratados con 1-MCP y con 1-MCP+emulsiones a las dos diluciones, la AT aumentó a valores promedio entre 0.86 y $1.11 \%$ de ácido málico y el pH a 3.74 (Cuadro 1).

Los cambios de color verde a verde-café en la cáscara de los frutos almacenados a $25^{\circ} \mathrm{C}$, se presentaron al día 8 de almacenamiento descendiendo el valor de ${ }^{\circ}$ Hue de 117.12 a 113.49. En los frutos GR y los tratados con emulsiones de candelilla y flava el color de la cáscara se mantuvo con valores de ${ }^{\circ} \mathrm{Hue}$ de 110-112 que corresponde a colores verdes por efecto daño por frío, ya que los frutos no maduraron (Cuadro 1).

En los frutos con 1-MCP, 1-MCP+C10:90 y 1-MCP+F10:90 el color en la cáscara disminuyó ligeramente a un tono verde-café hasta valores de ${ }^{\circ}$ Hue de 98.85-108 (Cuadro 1). Solo en los frutos con 1-MCP+ F15:85 se mostró una coloración en la cáscara ligeramente verde-amarillo $\left({ }^{\circ} \mathrm{Hue}=92\right)$, esto coincidió con lo reportado por Lima et al. (2004) en guanábana 'Morada' tratada con cera+1-MCP; concluyendo que este amarillamiento puede estar asociado con la degradación de la clorofila.

El $100 \%$ de los frutos GR y tratados con emulsiones en ambas diluciones almacenados a 16 ${ }^{\circ} \mathrm{C}$, desarrollaron síntomas de daño por frío como son: endurecimiento del fruto, pigmentos oscuros en la pulpa y oscurecimiento del eje central (Figura 3); el daño fue mayor al reportado por Espinosa et al. (2012) y pudo ser por la variabilidad en el índice de corte.

El 30\% de los frutos con 1-MCP desarrollaron síntomas de daño por frío en la cáscara; pero el 100\% de ellos no presentaron daño por frío aparente en la pulpa. Por otra parte, en los frutos tratados con 1-MCP+emulsiones, visualmente no hubo pigmentos oscuros ni en la cáscara ni en la parte comestible en el $100 \%$ de los frutos (Figura 3 ). Se ha reportado que el 1-MCP, inhbió el oscurecimiento de la pulpa del fruto eggplant (Solanum melongena) almacenada en refrigeración y estuvo asociado con la baja acumulación de fenoles totales y baja actividad de la polifenoloxidasa, así como la disminución del daño por frío (MASSOLO et al., 2011).

Por lo tanto existe la teoría de que el 1-MCP puede inhibir la acción de polifenoloxidasas y evitar el oscurecimiento, así como de otras enzimas que intervien en el endurecimiento del fruto aunque se requieren más estudios para comprobarlo. 

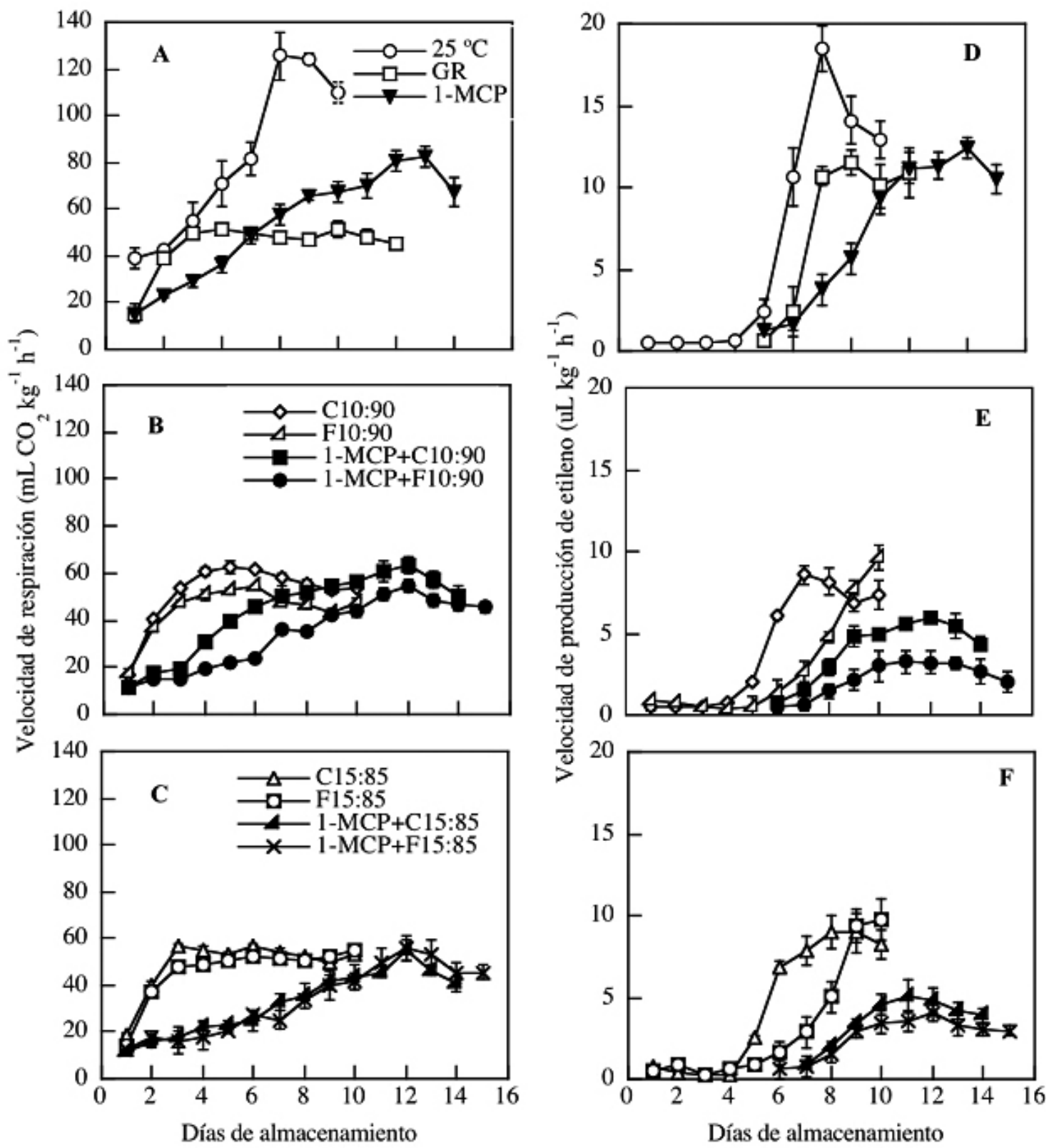

FIGURA 1- Velocidad de respiración y velocidad de producción de etileno en guanábana almacenada a $25{ }^{\circ} \mathrm{C}(\mathrm{A})$, a $16{ }^{\circ} \mathrm{C}(\mathrm{GR}, \mathrm{A})$, tratada con emulsiones a base de cera de candelilla y cera de abeja diluídas con agua en relación 10:90 y 15:85 v/v (C10:90, F10:90, C15:85 y F15:85) y almacenada a $16^{\circ} \mathrm{C}$ (B y E), tratada con $1500 \mathrm{~nL} \mathrm{~L}^{-1}$ de $1-\mathrm{MCP}$ por $12 \mathrm{~h}$ a $20^{\circ} \mathrm{C}$ y después almacenada a $16^{\circ} \mathrm{C}(1-\mathrm{MCP}$, A y D), y tratada con 1-MCP+emulsiones $(1-\mathrm{MCP}+\mathrm{C} 1090$, 1-MCP+F10:90, 1-MCP+C15:85 y 1-MCP+F15:85) como se mencionó anteriormente (C y F) almacenada a $16^{\circ} \mathrm{C}$. 

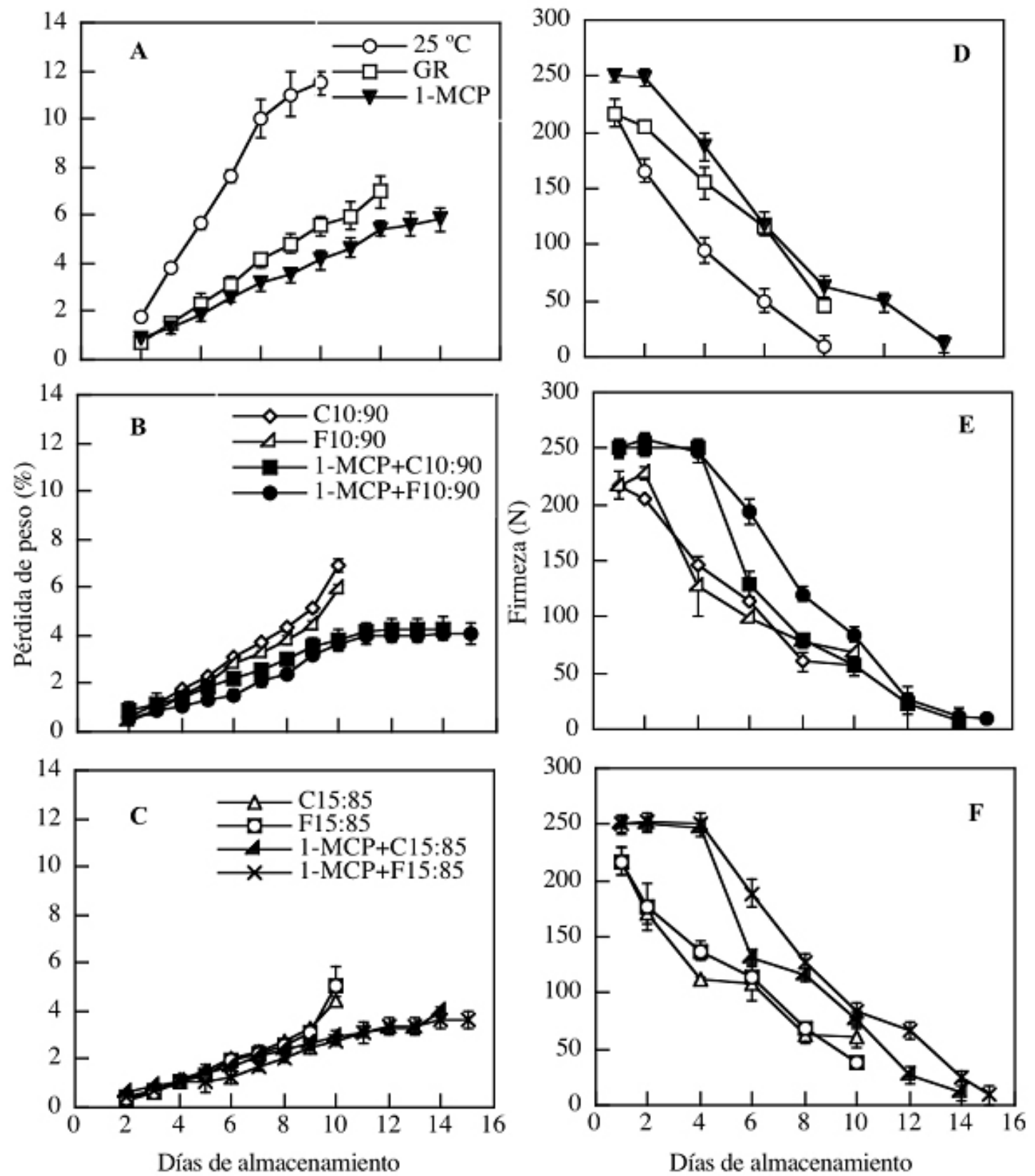

FIGURA 2- Porcentaje de pérdida de peso y firmeza en guanábana almacenada a $25^{\circ} \mathrm{C}(\mathrm{A})$, a $16{ }^{\circ} \mathrm{C}(\mathrm{GR}$, A), tratada con emulsiones a base de cera de candelilla y cera de abeja diluídas con agua en relación 10:90 y 15:85 v/v (C10:90, F10:90, C15:85 y F15:85) y almacenada a $16{ }^{\circ} \mathrm{C}$ (B y E), tratada con $1500 \mathrm{~nL} \mathrm{~L}^{-1}$ de $1-\mathrm{MCP}$ por $12 \mathrm{~h}$ a $20^{\circ} \mathrm{C}$ y después almacenada a 16 ${ }^{\circ} \mathrm{C}$ (1-MCP, A y D), y tratada con 1-MCP+emulsiones (1-MCP+C1090, 1-MCP+F10:90, 1-MCP+C15:85 y 1-MCP+F15:85) como se mencionó anteriormente (C y F) almacenada a $16{ }^{\circ} \mathrm{C}$. 


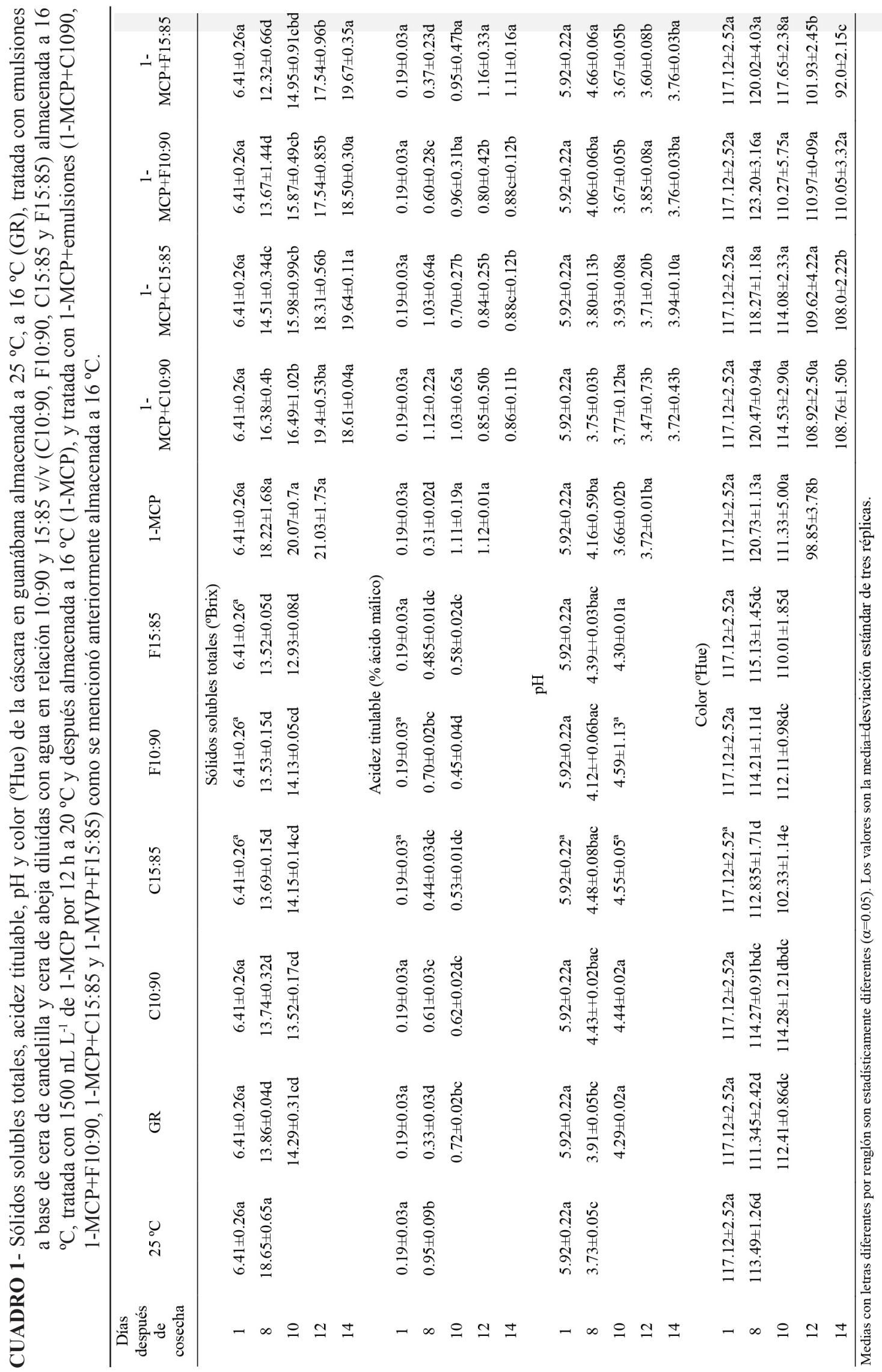


$16{ }^{\circ} \mathrm{C}$ (GR)
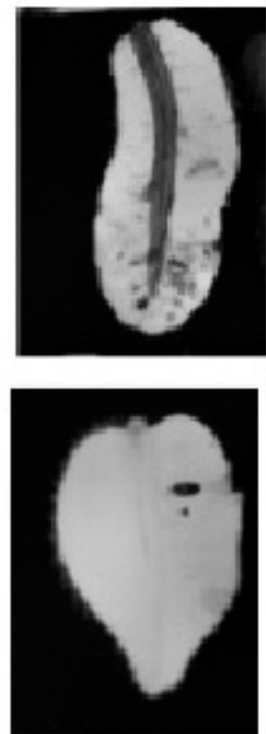

1-MCP
$\mathrm{C} 10: 90$
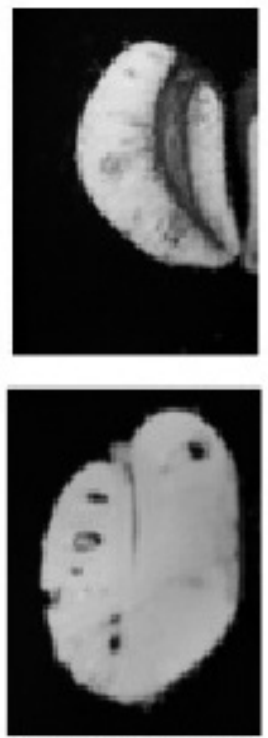

1-MCP+C10:90
F10:90
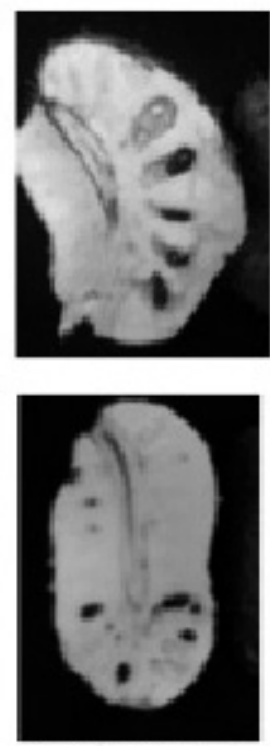

1-MCP+F10:90
C15:85
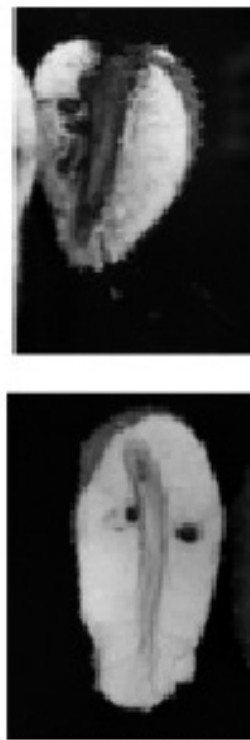

1-MCP+C15:85 l-MCP+Fl5:85
F15:85
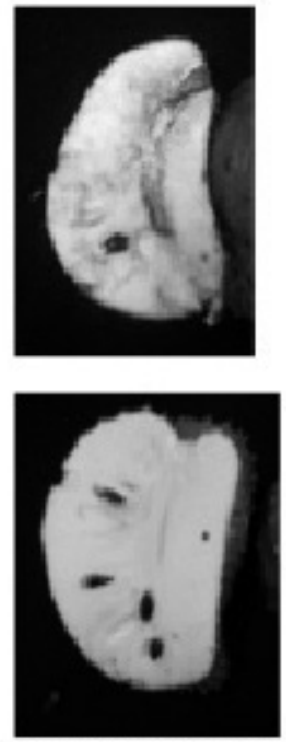

FIGURA 3- Fotografías de guanábanas con 10 días de almacenamiento a $16{ }^{\circ} \mathrm{C}(\mathrm{GR})$, con emulsiones a base de cera de candelilla y cera de abeja diluídas con agua en relación 10:90 y 15:85 v/v (C10:90, F10:90, C15:85 y F15:85) y almacenada a $16^{\circ} \mathrm{C}$, tratada con $1500 \mathrm{~nL} \mathrm{~L}^{-1}$ de $1-\mathrm{MCP}$ por $12 \mathrm{~h}$ a $20^{\circ} \mathrm{C}$ y después almacenada a $16^{\circ} \mathrm{C}(1-\mathrm{MCP})$, y tratada con $1-\mathrm{MCP}+$ emulsiones $(1-\mathrm{MCP}+\mathrm{C} 1090,1-\mathrm{MCP}+\mathrm{F} 10: 90,1-\mathrm{MCP}+\mathrm{C} 15: 85$ y 1-MCP+F15:85) como se mencionó anteriormente almacenada a $16^{\circ} \mathrm{C}$.

\section{CONCLUSION}

El almacenamiento a $16^{\circ} \mathrm{C} \sin$ o con emulsiones causó daño por frío a los frutos de guanábana. La aplicación de 1-MCP solo o combinado con las emulsiones, retrasaron la maduración de la guanábana e inhibieron los síntomas de daño por frío en la pulpa de los frutos, aunque la combinación de los mismos inhibió el $100 \%$ de daño por frío externo. El tratamiento de 1-MCP+F15:85 fue el que conservó la los frutos de guanábana por 14-15 días, tiempo suficiente para el traslado y venta del fruto en mercado locales.

\section{AGRADECIMIENTOS}

Los autores agradecen el financiamiento de FOMIX-COCYTEN. Al Lic. Joel Salomón Salas Praiz y al Sr. Jerónimo Curiel por donar los frutos de Guanábana. Se agradece también a la compañía Rohm and Haas (AgroFresh Inc. PA, USA) por la donación de SmartFresh ${ }^{\mathrm{TM}}$ Technology.

\section{REFERENCIAS}

AOAC. Official methods of analysis. $14^{\text {th }} \mathrm{ed}$. Arlington, 1984. p. 195, 417, 420.

BARITELLE, A.L.; HYDE, G.M.; FELLMAN, J.K.; VARITH, J. Using 1-MCP to inhibit the influence of ripening on impact properties of pear and apple tissue. Postharvest Biology and Technology, Amsterdam, v.23, n.2, p.153-160, 2001.

B L A NKESH I P, S.M.; D O LE, J.M. 1-Methylcyclopropene: a review. Postharvest Biology and Technology, Amsterdam, v.28, n.1, p.1-25, 2003.

CISNEROS, L.; KROCHTA, J.M. Internal modified atmospheres of coated fresh fruits and vegetables: understanding relative humidity effects. Journal of Food Science, Chicago, v.67, n.8, p.2792-2797, 2002. 
LIMA, M.A.C.; ALVES, R.E.; FILGUEIRAS, H.A.C. Comportamento respiratório e amaciamento de graviola (Annona muricata L.) após tratamentos pós-colheita com cera e 1-metilciclopropeno. Ciência e Agrotecnologia, Lavras, v.34, n.1, p.155$162,2010$.

LIMA, M.A.C.;ALVES, R.E.; FILGUEIRAS, H.A.C.; LIMA, J.R.G. Uso de cera e 1-metilciclopropeno na conservação refrigerada de Graviola (Annona muricata L.). Revista Brasileira de Fruticultura, Jaboticabal, v.26, n.3, p.433-437, 2004.

ESPINOSA, I.; ORTIZ, R.I.; TOVAR, B.; MATA, M.; MONTALVO, E. Fisiological and physicochemical behavior of soursop fruits refrigerated with 1-methylcyclopropene. Journal of Food Quality, Hoboken, v.36, n.1, p.10-20, 2012.

FALGUERA, V.; QUINTERO, J.P.; JIMÉNEZ, A.; MUÑOZ, J.A.; IBARZ, A. Edible films and coatings: structures, active functions and trends in their use. Trends in Food Science and Technology, Reino Unido, v.22, n.6, p.292-303, 2011.

JEONG, J.; HUBER, D.J.; SARGENT, S.A. Influence of 1-methylcyclopropene (1-MCP) on ripening and cell-wall matrix polysaccharides of avocado (Persea americana) fruit. Postharvest Biology and Technology, Amsterdam, v.25, n.3, p.241-256, 2002.

JIANG, J.M.; JOYCE, D.C.; JIANG, W.; LU, W.J. Effects of chilling temperatures on ethylene binding by banana fruit. Plant Growth Regulation, New York, v.43, n.1, p.109-115, 2004

MASSOLO, J.F.; CONCELLÓN, A.; CHAVES, A.R.; VICENTE, A.R. 1-Methylcyclopropene (1MCP) delays senescence, maintains quality and reduces browning of non-climacteric eggplant (Solanum melongena L.) fruit. Postharvest Biology and Technology, Amsterdam, v.59, n.1, p.10-15, 2011.

PAREEK, S.; YAHIA, E.M.; PAREEK, O.P.; KAUSHIK, R.A. Postharvest physiology and technology of Annona fruits. Food Research International, Guelph, v.44, n.7, p.1741-1751, 2011.
PIRIYAVINIT, P.; KETSA, S.; VAN DOORN, W.G. 1-MCP extends the storage and shelf life of mangosteen (Garcinia mangostana L.) fruit. Postharvest Biology and Technology, Amsterdam, v.61, n.1, p.15-20, 2011.

SAUCEDO, S.; ROJAS, R.; AGUILERA, A.; SAENZ, A.; DE LA GARZA, H.; JASSO, A.; AGUILAR, C. Edible film based on candelilla wax to improve the shelf life and quality of avocado. Food Research International, Guelph, v.42, n.1, p.511-515, 2009.

TIWARI, K.; PALIYATH, G. Microarray analysis of ripening-regulated gene expression and its modulation by 1-MCP and hexanal. Plant Physiology and Biochemistry, Bari, v.49, n.3, p.329-340, 2011.

TOVAR, B.; GARCÍA, H.S.; MATA, M. Physiology of pre-cut mango I ACC and ACC oxidase activity of slices subjected to osmotic dehydration. Food Research International, Guelph, v.34, n.2-3, p.207215, 2001

ZHANG, Z.; HUBER, D.J.; RAO, J. Ripening delay of mid-climacteric avocado fruit in response to elevated doses of 1-methylcyclopropene and hypoxia-mediated reduction in internal ethylene concentration. Postharvest Biology and Technology, Amsterdam, v.60, n.2, p.83-91, 2011.

ZHOU, R.; LI, Y.; YAN, L.; XIE, J. Effect of edible coatings on enzymes, cell-membrane integrity, and cell-wall constituents in relation to brittleness and firmness of Huanghua pears (Pyrus pyrifolia Nakai, cv. Huanghua) during storage. Food Chemistry, London, v.124, n.1, p.569-575, 2011 